\title{
INOVANDO COM DEMOCRACIA, AINDA UMA UTOPIA
}

Fernando G. Tenório*

\section{Introdução}

O propósito deste ensaio é contribuir para a discussão, no âmbito do Comitê Técnico do Programa Gestão Pública e Cidadania, do significado de inovação na gestão pública. Um dos objetivos desse Programa (PGPC) é "descobrir as inovações e os inovadores nos níveis de governo subnacional" ${ }^{2}$. Três são os incentivos para participar desse debate: a) estudos desenvolvidos no Programa de Estudos em Gestão Social (PEGS); b) o ensaio Inovação na gestão pública no Brasil. uma aproximação teórico-conceitual; c) a cidadania ainda ser um conceito utópico no Brasil.

a) No PEGS, que é uma linha de pesquisa implementada na Escola Brasileira de Administração Pública (EBAP) da Fundação Getúlio Vargas

\footnotetext{
* Professor Adjunto da EBAP /FGV, Coordenador do PEGS e membro do Comitê Técnico do Programa Gestão Pública e Cidadania.

${ }^{1}$ Iniciativa da Escola de Administração de Empresas de São Paulo da Fundação Getúlio Vargas (EAESP/FG) e da Fundação Ford, e conta com o apoio do Banco Nacional de Desenvolvimento Econômico e Social (BNDES).

${ }^{2}$ Os outros objetivos são: focalizar e disseminar o que está indo bem na administração pública; aumentar o estoque de conhecimento sobre experiências alternativas em gestão pública; premiar as melhores iniciativas.
} 
(FGV - Rio), procurou estudar as relações entre a Sociedade e o Estado, assim como entre o trabalho e o capital. Geralmente, este tipo de discussão é pautado pela seqüência linear Estado-Sociedade e capital-trabalho. Entretanto, na perspectiva deste estudo, propositalmente, focalizamos a relação invertendo a posição dessas categorias de análise: Sociedade-Estado e trabalhocapital. Aparentemente, esta mudança de posição dos temas não contribui, substantivamente, para uma análise dos fenômenos políticos, sociais e econômicos por eles gerados. No entanto, ao tomar como premissa que o estudo deve partir da ótica da Sociedade e da ótica do trabalho, acreditamos mudar o enfoque de quem deve ser o protagonista no processo dessas relações - a cidadania. Portanto, o cidadão é o sujeito privilegiado de vocalização daquilo que interessa à Sociedade nas demandas ao Estado e daquilo que interessa ao trabalhador na interação com o capital. Isto é, a cidadania é vista não apenas como a base da soberania de um Estadonação, mas também como expressão do pleno exercício de direitos exigíveis em beneficio da pessoa humana e da comunidade.

b) No artigo Inovação na gestão pública no Brasil: uma aproximação teórico-conceitual, dos Profs. Pinho e Santana (1988), são identificadas cinco categorias que poderiam contribuir para discutir o conceito de inovação na gestão pública: gestão democrática, descentralização e desburocratização dos serviços públicos; incorporação dos excluídos (maiorias) e minorias; valores para trás, valores para frente. Embora os autores alertem "que essas categorias não esgotam as possibilidades de inovação" (pinho, 1998: 8), neste ensaio focalizaremos duas dessas categorias: gestão democrática [b1] e valores para frente [b2], na medida em que elas têm afinidade com o conceito de gestão social [b3] utilizado no âmbito do PEGS.

b.1) Por gestão democrática os autores entendem "uma gestão participativa, comunitária, sem paternalismo, com combate ao clientelismo"; "pode ser vista também como a deselitização de políticas públicas, facilitando o acesso de bens normalmente direcionados a uma elite, uma minoria"; a gestão democrática é aquela também "que busca a participação de uma maneira mais ampla mas também localizada" (pinho e Santana, 1988: 9). O exercício da cidadania, o cidadão como sujeito e não objeto, parece ser o eixo central do conceito de gestão democrática trabalhado por Pinho e Santana.

b.2) Já a categoria valores para frente significaria "valores que não existiam até recentemente e que começam a ser cultivados no presente como resultado de uma nova configuração econômica, social e política" (pinho e Santana, 1998: 11). Parece ser este o caso do Brasil. A partir 
principalmente da Constituição de 1988, que foi denominada, quando do término dos trabalhos da Assembléia Constituinte, de Constituição Cidadã, dado que a cidadania foi o ethos central da discussão de toda Assembléia, esse valor passou a se incorporar, daí em diante, à discussão da agenda brasileira.

b.3) Por gestão social entendemos a substituição da gestão tecnoburocrática, monológica, por um gerenciamento participativo, dialógico, no qual o processo decisório em uma dada sociedade é exercido por meio dos diferentes sujeitos sociais. Este conceito sugere que a pessoa humana, ao tomar ciência de sua função como sujeito social e não adjunto, ou seja, tendo conhecimento da substância social do seu papel na organização da sociedade, deve atuar não somente como contribuinte, eleitor, trabalhador, mas com uma presença ativa e solidária nos destinos de sua comunidade.

c) Finalmente e apesar de [b2], consideramos que a cidadania ainda não é um valor comunitário ideal, utópico, livre de conflitos na sociedade brasileira. Aqui esta variável social ainda não é plenamente considerada, quer nas discussões parlamentares, em que salvo exceções, a política como um bem comum é substituída pelos interesses corporativos e/ou fisiológicos, quer nos ambientes das burocracias públicas onde esta variável tem servido mais como expressão de retórica dos tecnoburocratas do que para atender as necessidades da cidadania substantiva.

Procurando melhor delimitar esta proposta de discussão, sistematizaremos o presente texto obedecendo à seguinte estrutura: I identificação dos institutos constitucionais que referenciam o papel da cidadania na gestão pública; II - a partir da descrição do referencial teórico de Jürgen Habermas, aproximar-nos-emos do conceito de cidadania deliberativa; III - conclusão, na qual serão apontadas algumas inquietações e proposições no que diz respeito à possibilidade de envolvimento pleno da cidadania nas políticas públicas de governos subnacionais.

\section{Elementos constitucionais}

Se considerarmos que inovar significa tornar novo, introduzir novidades, a historiografia de inovação na burocracia pública brasileira vem, desde os anos 30, sendo alvo de diferentes propostas de mudança na sua estrutura legal, organizacional e operacional. Propostas originadas, na maioria das vezes, no setor público federal são reproduzidas ou têm efeitos sistêmicos, nos poderes públicos dos Estados e municípios da federação. 
Com a Constituição de 88, denominada Constituição Cidadã surge, de maneira enfática, o papel do cidadão junto aos poderes públicos. E as recentes propostas de mudança da burocracia pública brasileira, notadamente aquelas contempladas no Plano Diretor da Reforma do Aparelho do Estado (1995), propõem quatro processos para a reforma, entre os quais destacamos o seguinte:

"(c) o aumento da governabilidade, ou seja, do poder do governo, graças à existência de instituições politicas que garantam uma melhor intermediação de interesses e tornem mais legitimos e democráticos os governos, aperfeiçoando a democracia representativa e abrindo espaço para o controle social ou democracia direta” (Pereira, 1997: 19).

Por sua vez, a Constituição Federal de 1988 define, no seu artigo primeiro, parágrafo único, a natureza e a finalidade do Estado brasileiro que se deseja instituir bem como seus fundamentos:

"Art. $1^{\circ}$ A República Federativa do Brasil formada pela união indissolúvel dos Estados e Municípios e do Distrito Federal constitui-se em Estado Democrático de Direito e tem como fundamentos:

I - a soberania;

11 - a cidadania (grifo nosso);

111 - a dignidade da pessoa bumana;

111 - a dignidade da pessoa bumana;

Parágrafo único. Todo o poder emana do povo, que o exerce por meio de representantes eleitos ou diretamente, nos termos desta Constituição”.

A democracia participativa nos termos da Constituição Federal de 1988 é, portanto, entendida como elemento intrínseco do Estado Democrático de Direito, "processo de convivência social numa sociedade livre, justa e solidária (Art. $3^{\circ}, \mathrm{II}$ ), em que o poder emana do povo e deve ser exercido em proveito do povo, diretamente ou por representantes eleitos (Art. $1^{\circ}$ ); participativa, porque envolve a participação crescente do povo no processo decisório e na formação dos atos de governo" (Silva e D’arc, 1996: 120).

Os constituintes entenderam, portanto, que o regime político brasileiro deveria ser uma democracia semidireta, combinando elementos de participação indireta (representação) e de participação direta. Segundo o princípio participativo, foram acolhidos na Constituição diversos institutos jurídicos nos capítulos referentes ao planejamento e gestão de 
políticas públicas, fiscalização da administração pública, defesa e garantia de direitos coletivos, gestão de empresas privadas e vida política em geral.

A Constituição Federal de 1988 estabelece os seguintes institutos jurídicos sobre participação popular: ${ }^{3}$

a) Iniciativa Popular (art. 14, III, 27, 29, XI e 61, \ $2^{\circ}$ ): participação popular no processo legislativo, através da apresentação de projetos de lei para apreciação pelo Poder Legislativo. No caso da União, o projeto popular deve ser subscrito por, no mínimo, um por cento do eleitorado nacional, distribuído pelo menos em cinco Estados, com não menos de três décimos por cento dos eleitores de cada um deles ${ }^{4}$.

b) Referendo (art. 14, II e 49, XV): forma de consulta popular em que os projetos de lei aprovados pelo legislativo devem ser submetidos à aprovação popular para que possam entrar em vigor.

c) Plebiscito (art. 14, I e 18, \\ $3^{\circ}$ e $4^{\circ}$ ): consulta popular semelhante ao referendo. Difere deste na medida em que se trata de submeter previamente à aprovação popular um projeto de lei, antes de levá-lo à apreciação do Poder Legislativo.

d) Colegiados de Órgãos Públicos (art. 10): assegura a participação de trabalhadores e empregadores nos colegiados de órgãos públicos em que seus interesses profissionais ou previdenciários sejam objeto de discussão e deliberação.

e) Planejamento Público (art. 29, XII): estabelece a obrigatoriedade de participação no planejamento público, em nível municipal, das associações representativas.

j) Seguridade Social (art. 194, \ único, VII): determina o caráter democrático e descentralizado da gestão administrativa da seguridade social, ou seja, dos direitos relativos à saúde, previdência e assistência social. $\mathrm{O}$ aspecto democrático remete à participação da comunidade, em especial dos trabalhadores, empresários e aposentados, na gestão, conforme dispuser a lei de organização de cada setor.

\footnotetext{
${ }^{3}$ Sumário feito de acordo com Dantas, José Lucena. "O direito de participação na Constituição Federal de 1988” (resenha). Rio de Janeiro: Centro Brasileiro de Cooperação e Intercâmbio de Serviços Sociais - CBCISS, $\mathrm{n}^{\circ} 234,1991$.

${ }^{4}$ No caso dos municípios, a Constituição determina que a iniciativa popular deverá ser subscrita por, no mínimo, cinco por cento do eleitorado. Não existe iniciativa popular em matéria constitucional. Apesar da dificuldade interposta em termos numéricos, a admissão da iniciativa popular representa uma quebra no poder de propor leis, antes exclusivo do Executivo e Legislativo.

${ }^{5}$ O disposto neste artigo seria levado em conta quando da aprovação do Sistema Único de Saúde (SUS), artigo 198, I e III, bem como na Lei de Organização da Assistência Social (LOAS).
} 
g) Ensino Público (art. 206, VI): admite-se, em caráter genérico, a gestão democrática do ensino publico, remetendo-se à lei sua regulamentação .

b) Cultura (art. 216, $\int 1^{\circ}$ ): prevê a participação da comunidade, juntamente com o Poder Público, em todas as ações voltadas à defesa e promoção do patrimônio cultural.

i) Atendimento aos direitos da criança e do adolescente (art. 227, \ $7^{\circ}$ ): estabelece como dever da família, da sociedade e do Estado assegurar à criança e ao adolescente, com absoluta prioridade, o direito à vida, à saúde, à alimentação, à educação, ao lazer, à profissionalização, à cultura, à dignidade, ao respeito, à liberdade e à convivência familiar e comunitária .

As constituições estaduais e leis orgânicas municipais, de acordo com as normas da federação brasileira, seguiram os princípios fundamentais da Constituição Federal. A Constituição Federal, no Brasil, é rígida e limita a autonomia dos entes da federação, isto é, "nem o governo federal, nem os governos dos Estados, nem os dos municípios ou do Distrito Federal são soberanos, porque todos são limitados, expressa ou implicitamente, pelas normas positivas daquela lei fundamental. Exercem suas atribuições nos termos nela estabelecidos" (Silva e D'arc, 1996: 49).

Entendida a constituição "como interpretação e configuração de um sistema de direitos que faz valer o nexo interno entre autonomia privada e pública" (Habermas, 1997: 346, vol. I), passaremos a descrever a relação conceitual entre cidadania liberal, republicana e deliberativa.

\section{Cidadania deliberativa}

A fim de complementar a leitura dos institutos jurídicos estabelecidos na Constituição brasileira, focalizaremos o pensamento teórico-social de

\footnotetext{
${ }^{6}$ Decisão do Supremo Tribunal Federal julgou inconstitucional a eleição para os cargos de diretores de escolas públicas alegando que são cargos comissionados, portanto não podendo ser escolhidos em eleições diretas pelas comunidades escolares. "A base dos julgamentos do STF dessas ações tem sido o artigo 37, inciso 2 da Constituição, segundo o qual a 'investidura em cargo ou emprego público depende de aprovação prévia em concurso público de provas ou de provas de títulos, ressalvadas as nomeações para cargo em comissão declarado em lei de livre nomeação e exoneração"' (Carneiro, 1999: 5).

${ }^{7}$ No parágrafo $7^{\circ}$, fixa-se que as diretrizes relativas à política de proteção à infância e adolescência devem levar em conta a descentralização político-administrativa e a participação de organizações representativas da sociedade na formulação das políticas e no controle das ações em todos os níveis. "Essas diretrizes foram incorporadas ao Estatuto da Criança e do Adolescente, aprovado pelo Congresso Nacional, o qual, além de estabelecer a forma e os mecanismos do exercício dos direitos, adotou a organização descentralizada do atendimento e instituiu os Conselhos Comunitários" (Dantas, 1991: 9).
} 
Jürgen Habermas, que desenvolve uma análise comparativa entre os "tipos ideais", classificatórios, de politica liberal, republicana e deliberativa. No entanto, antes disso, cabe uma observação prévia a respeito da utilização neste ensaio da teoria social habermaseana.

Os estudos habermaseanos para fazer a distinção entre estas três formas de politicas, originam-se da compreensão norte-americana sobre o significado das concepções liberal e republicana, para chegar a uma terceira: "concepção procedimental de política deliberativa" (Habermas, 1995: 39). Embora os contextos sócio-político-econômicos, tanto o estadunidense quanto o habermaseano, sejam diferentes do brasileiro, primeiro mundo - EUA e Alemanha, do terceiro mundo - Brasil, a proposta de J. Habermas enquanto teoria social, isto é, enquanto referência conceitual, à semelhança de outras, também estimula a discussão que pretendemos focalizar neste ensaio. Habermas é considerado um dos principais filósofos da atualidade e a sua produção teórica vem dos anos 50 aos nossos dias. Portanto, a compreensão dos conceitos de cidadania liberal, republicana e deliberativa, não pode estar dissociada do conjunto de sua obra bem como da intenção de qualquer proposta teórico-crítica: definição de conteúdos que orientem processos de reconstrução epistemológica.

Esta observação prévia é para não caracterizar a descrição do conceito de cidadania deliberativa como ingênua na medida em que, a princípio, tal conceito seria aplicável somente a sociedades desenvolvidas. Como referência epistemológica, isto é, como insinuação de um conhecimento que pode ser (re)orientador de outros, particularmente daqueles dirigidos à dialogicidade, à intersubjetividade visando a democratização dessa relação social, o conceito de cidadania deliberativa originado de Jürgen Habermas contribui para o intento. Segundo o próprio autor, "uma sociologia reconstrutiva da democracia tem que escolher seus conceitos básicos de tal modo que estes permitam identificar nas práticas políticas fragmentos e partículas de uma 'razão existente', mesmo que distorcida" (Habermas, 1997: 9, V II).

O estudo comparativo dos conceitos de politica liberal, republicana e deliberativa pode ser feito a partir de Três Modelos Normativos de Democracia (Habermas: 1995), assim como de Direito e democracia: entre facticidade e validade (Habermas: 1997, V I e 1I). O primeiro foi publicado em 1991, após conferência de Habermas sobre "Teoria da democracia" na Universidade de Valência, em outubro de 1991.

O primeiro estudo tem início com o significado de ação política, 
que caracterizaria, de acordo com a análise habermaseana, a diferença entre estes "enfoques rivais" no processo democrático.

"Segundo a concepção liberal, o processo democrático cumpre a tarefa de programar o Estado no interesse da sociedade, entendendose o Estado como o aparato de administração pública e a sociedade como o sistema, estruturado em termos de uma economia de mercado, de relações entre pessoas privadas e do seu trabalho social. A politica (no sentido da formação política da vontade dos cidadãos) tem a função de agregar e impor os interesses sociais privados perante um aparato estatal especializado no emprego administrativo do poder politico para garantir fins coletivos" (Habermas, 1995: 39).

Nessa percepção os indivíduos atuam em função de seus interesses pessoais, porém em consonância com as leis do Estado. O Estado, através da administração pública, implementa negociações com as pessoas privadas, com a sociedade civil. No entanto, a orientação ideológica dessa percepção é o mercado onde interesses egoístas são direcionados, calculados, estrategicamente visando antes o sucesso que a solidariedade, interesses sociais privados que o bem comum. Contrária a essa posição da política liberal que atua como mediadora entre o Estado e os civis, na politica republicana estes são orientados para a pólis, para o bem comum.

"Segundo a concepção republicana, a politica não se esgota nessa função de mediação. Ela é um elemento constitutivo do processo de formação da sociedade como um todo. A política é entendida como uma forma de reflexão de um complexo de vida ético (no sentido de Hegel). Ela constitui o meio em que os membros de comunidades solidárias, de caráter mais ou menos natural se dão conta de sua dependência recíproca, e, com vontade e consciência, levam adiante essas relações de reconhecimento reciproco em que se encontram, transformando-as em uma associação de portadores de direitos livres e iguais" (Habermas, 1995: 39 - 40).

A conseqüência dessa análise do processo político são as duas formas de cidadão daí resultantes. O conceito de cidadão na perspectiva liberal é definido em função dos "direitos subjetivos que eles têm diante do Estado e dos demais cidadãos (...) em prol de seus interesses privados dentro dos limites estabelecidos pelas leis" (Habermas, 1995: 40). Já de acordo com o conceito republicano, o cidadão não é aquele que usa a liberdade só para desempenho como pessoa privada, mas tem na participação uma prática comum "cujo exercício é o que permite aos cidadãos se converterem no que querem ser: atores políticos responsáveis de uma comunidade de 
pessoas livres e iguais", já que se espera dos cidadãos "muito mais do que meramente orientarem-se por seus interesses privados" (Habermas, 1995: 41). Daí derivam as seguintes inferências:

"Na interpretação libera" o status de cidadão determina-se primariamente a partir dos direitos negativos que eles possuem em relação ao Estado e outros cidadãos. Enquanto portadores desses direitos, eles gozam, não somente da proteção do Estado, na medida em que perseguem seus interesses privados no âmbito de limites traçados por leis, como também da proteção contra intervenções do Estado que ultrapassam o nivel de intervenção legal. Os direitos políticos (...) proporcionam aos cidadãos a possibilidade de fazer valer seus interesses privados, que no final - através da formação do governo) da composição de corporações parlamentares $e$ de votações - eles se agregam com outros interesses privados) formando uma vontade politica que influencia a administração (...). $\mathrm{Na}$ interpretação. Republicana, o status dos civis não se determina pelo modelo das liberdades negativas que essas pessoas privadas, enquanto tais, podem reclamar. Os direitos dos cidadãos, em primeira linha os direitos políticos de participação e de comunicação, são, ao invés, liberdades positivas. (...) Nesta medida, o processo político não serve apenas ao controle da atividade do Estado através de civis (...). Tamponco ele preenche uma função de charneira entre o Estado e a sociedade. Ele resulta do poder produzido comunicativamente na prática de auto-determinação de cidadãos e se legitima pelo fato de proteger essa prática através da institucionalização da liberdade pública. (...) Com isso, exigese do cidadão republicano muito mais do que a simples orientação pelo próprio interesse" (Habermas, 1997: 334-35) vol. I) ${ }^{8}$.

A esta análise comparativa de "tipos ideais", Habermas vai acrescentar uma outra maneira conclusiva do significado de cidadão: 0 modelo da deliberação. Proposta que Habermas "gostaria de defender", pois apóia-se "nas condições de comunicação" e "renova-se na rememoração ritual do ato de fundação republicana" (Habermas, 1995: 45-46), concepção de cidadania que está assentada no significado de ações comunicativas, voltadas para o entendimento, ao invés de ações estratégicas, voltadas para o êxito.

\footnotetext{
${ }^{8}$ Habermas aponta a vantagem e a desvantagem do modelo republicano: "A vantagem, vejo-a em que se atém ao sentido democrata radical de uma auto-organização da sociedade por cidadãos unidos comunicativamente, e em não fazer com que os fIns coletivos sejam derivados somente de um arranjo entre interesses privados conflitantes. Vejo sua desvantagem no idealismo excessivo que há em tornar o processo democrático dependente das virtudes de cidadãos orientados para o bem comum" (Habermas, 1995: 44).
} 
O processo da política deliberativa não fica restrito as corporações parlamentares, mas orienta-se através da esfera pública política fundada numa teoria de discurso, de pressupostos comunicativos e procedimentais, sob a qual o processo deliberativo surge por meio do melhor argumento, da ação comunicativa. Ação em que os sujeitos sociais, ao fazerem suas propostas, têm de apresentá-las em bases racionais, quer dizer, nenhuma das partes pode impor suas pretensões de validade sem que haja um acordo alcançado comunicativamente, no qual todos os participantes expõem os seus argumentos. Existe argumento quando os requisitos de validade se tornam explícitos em termos de até que ponto podem ser oferecidas boas razões, portanto, discursivamente. Quem fala expõe suas idéias de maneira racional e quem ouve reage tomando posições motivadas também pela razão. Ou seja, dizer que alguém está atuando racionalmente ou que um enunciado é racional, é como dizer que a ação ou o enunciado pode ser criticado ou defendido pela pessoa ou pelas pessoas implicadas, de tal modo que estas possam justificá-los ou fundamentá-los. Neste tipo de ação social, as pessoas envolvidas entram em acordo para coordenar seus planos de ação, nos quais o ajuste alcançado é avaliado pelo reconhecimento intersubjetivo das pretensões de validade do discurso de cada um dos sujeitos envolvidos.

"Conforme essa concepção [cidadania deliberativa] a razão prática se afastaria dos direitos universais do homem (liberalismo) on da eticidade concreta, de uma determinada comunidade (comunitarismo) para se situar naquelas normas de discurso e de formas de argumentação que retiram seu conteúdo normativo do fundamento da validade da ação orientada para o entendimento, e, em última instância, portanto, da própria estrutura da comunicação lingüística” (Habermas, 1995:46).

O significado de cidadania deliberativa procura superar a concepção liberal assim como a republicana por meio da soberania popular. No primeiro caso os indivíduos cedem ao poder político parte de seus direitos, e este tem a função de arbitrar os conflitos entre os interesses privados e sociais. No segundo, o poder político é o administrador e fiador da soberania do povo e instrumento de construção da sociedade.

Já o conceito de soberania popular tem a ver com a perspectiva de um processo permanente de intercâmbio comunicativo e de formação de opinião pública. Esta se articula por meio da intersubjetividade e da interação permanente dos membros de uma sociedade atuando sob a força social integradora da solidariedade. "Somente quando esta trama comunicativa permite este exercício permanente de direitos individuais e 
de expressão social, pode desenvolver-se uma dinâmica de relações entre a sociedade civil e o Estado (...)" (Boladeras, 1996: 149).

Com o conceito de cidadania deliberativa, fundamentada na noção habermaseana de ação comunicativa (perspectiva crítica e auto-reflexiva), esboça-se a imagem de uma sociedade descentralizada, que se caracteriza por um espaço público que serve para apresentar, identificar e solucionar problemas sociais. Nesse tipo de cidadania, a solução das questões subnacionais, por exemplo, não deve ser planejada exclusivamente pelo poder político e/ou tecnoburocrático ou atender a interesses sociais corporativos, mas compartilhar com a sociedade civil por meio de um procedimento político argumentativo no qual a cidadania delibera, decide, com os outros poderes, os interesses da comunidade.

Portanto, essa concepção de cidadania deve ser entendida como uma ação politica deliberativa, na qual o indivíduo deve participar de um procedimento democrático, decidindo, nas diferentes instâncias de uma sociedade e em diferentes papéis, o seu destino social como pessoa humana, quer como eleitor, trabalhador ou consumidor, ou seja, a sua autodeterminação não se dá, exclusivamente, sob a lógica do mercado ou da tecnoburocracia estatal mas da democracia social: igualdade política e decisória. Esta concepção de cidadania deliberativa permite-nos concluir que Habermas defende a posição segundo a qual o cidadão deve ser democraticamente ativo, ou seja, os indivíduos podem influir concretamente na transformação de sua própria situação no âmbito em que vivem e atuam.

\section{Conclusão, ainda uma utopia}

A partir dos três incentivos apontados na introdução deste ensaio (a) estudos desenvolvidos no Programa de Estudos em Gestão Social (PEGS); b) o ensaio Inovação na gestão pública no Brasil: uma aproximação teórico-conceitual; c) a cidadania ainda é um conceito utópico no Brasil) e considerando os conteúdos dos itens I e II, referencial constitucional e teórico-social, pretendemos concluir este ensaio apontando, por um lado, algumas inquietações que podem reforçar a posição de que a cidadania no Brasil ainda é uma utopia e, por outro, proposições gerais em direção à utopia.

As inquietações serão referenciadas a partir das 300 experiências semifinalistas avaliadas nos anos de 1996, 1997 e 1998 no concurso promovido pelo Programa Gestão Pública e Cidadania. Avaliação que tinha como objetivo central verificar se as propostas de participação 
popular utilizados nos programas e/ou projetos corroboravam a pretensão do envolvimento de uma cidadania ativa, deliberativa.

Uma observação nesta conclusão é quanto ao método de análise empregado nos 300 programas e/ou projetos estudados. O método foi o de análise temática, "que consiste em descobrir núcleos de sentido que compõem uma comunicação cuja presença ou freqüencia signifiquem alguma coisa para o objetivo analítico visado" (Minayo, 1998: 209). Neste caso, procurávamos aquelas expressões descritas nos documentos enviados ao Programa Gestão Pública e Cidadania, que significassem o envolvimento da cidadania nos processos decisórios dos programas e/ ou projetos semifinalistas.

Apesar da palavra utopia, derivada do grego, significar "nenhum lugar", muitas formas de pensamento e/ou projetos sociais possuem elemento utópico, e é assim que pretendemos entender esta expressão. No caso específico deste ensaio, a cidadania deliberativa, como utopia, seria um valor comunitário ideal que contribuiria, por meio de ações comunicativas, com os governos subnacionais - estaduais e/ou municipais - para a solução de problemas ali existentes. Ou seja, uma cidadania ativa e não dependente exclusivamente dos poderes executivo, legislativo e judiciário, em que a relação entre a sociedade civil e o Estado se daria pela ótica da primeira.

A partir das propostas de participação popular identificadas nos 300 semifinalistas e tendo como referência de análise a utopia de uma cidadania comunitária, deliberativa, envolvida com o poder público de forma solidária na solução de suas necessidades, algumas questões foram percebidas nesta análise e contribuem para reforçar a hipótese de que a inovação da burocracia pública brasileira dos governos subnacionais por meio da participação popular ainda é uma utopia.

Os 300 projetos analisados não apresentaram resultados substantivamente diferentes quanto à participação da cidadania. Parece que os governos estaduais e municipais desenvolvem seus projetos ainda dependentes de situações estruturais - política, econômica e social - que dificultam as inovações pretendidas com o envolvimento de setores organizados da sociedade e/ou da cidadania propriamente dita. Embora soluções criativas sejam propostas, alguns elementos, ainda que de caráter genérico, podem ser apontados como inquietantes ou impeditivos da prática democrática na gestão da res pública subnacional: 
- Viés burocrático e/ou tecnoburocrático na concepção da participação da cidadania nos programas e/ou projetos.

- Práticas gerenciais enfocadas em resultados e não em processos de envolvimento da cidadania.

- O exercício da participação popular implementado, na maioria das vezes, em programas e/ou projetos de baixo custo orçamentário.

- O envolvimento da cidadania como retórica e não como ação efetiva no processo de tomada de decisão das políticas públicas.

Parece, portanto, que o processo político no Brasil orienta-se mais no sentido o "tipo" de política liberal, na qual processos estratégicos, monológicos, sobrepõem-se tanto àqueles de procedimento participativo, de politica republicana como a argumentativo, de política liberal, na qual a cidadania participa decidindo com o setor público.

Se considerarmos as afinidades entre os estudos desenvolvidos no PEGS, o conceito de gestão democrática e valores para frente dos professores Pinho e Santana os institutos jurídicos pontificados na Constituição Federal de 1988 e a definição de cidadania deliberativa de Jürgen Habermas, chegaremos à conclusão, a partir dos 300 casos analisados, que, salvo exceções, a prática da inovação gestão dos governos subnacionais no Brasil por meio da participação da cidadania ainda é uma utopia, ou melhor é uma distopia. Distopia na medida em que conhecimento exercitado pelas propostas de participação da cidadania em programas e/ou projetos subnacionais parece estar fundado em uma anomalia congênita da tecnoburocracia pública brasileira ou, de maneira mais otimista em uma pedagogia diretiva ao invés de emancipatória, na qual as práticas sociais tradicionais são transformadas em procedimentos dialógicos.

Portanto, inovar na gestão pública de governos subnacionais, por que não é guardar razoabilidade com os preceitos constitucionais e com processos politicos deliberativos - ou seja, de uma cidadania ativa, que atue no entendimento com o Estado, na solução comunitária de seus problemas. Para atuar com inovação, com democracia, os governos subnacionais deveriam ao menos:

- reconhecer que a comunidade tem capacidade de contribuir para o seu próprio desenvolvimento;

- trabalhar com a participação da comunidade em todo o processo de planejamento da política pública;

- compreender os valores, costumes, crenças, necessidades e objetivos da comunidade; 
- delegar permanentemente o poder ao pessoal que trabalha no nível operacional;

- fazer com que a tecnoburocracia atue numa perspectiva de funcionário para cidadão-funcionário.

\section{Bibliografia}

BRASIL. Constituição da República Federativa do Brasil. Senado Federal, Centro Gráfico, 1994.

FUJIWARA, Luis Mario et. ali. 20 experiências de gestão pública e cidadania. São Paulo: Programa Gestão Pública e Cidadania, 1999.

HABERMAS, Jürgen. Três modelos normativos de democracia. Lua Nova - Revista de Cultura e Política. São Paulo: Centro de Estudos de Cultura Contemporânea, (36): 39-53, 1995.

Direito e democracia: entre facticidade e validade. Rio de Janeiro: Tempo Brasileiro, 1997, Vol. I e 11.

MINAYO, Maria Cecília de S. O desafio do conhecimento: pesquisa qualitativa em saúde. Rio de Janeiro - São Paulo, Hucitec - Abrasco, 1998.

PEREIRA, Luiz Carlos Bresser. A reforma do Estado dos anos 90: lógica e mecanismos de controle. Brasília: Ministério da Administração Federal e Reforma do Estado, 1997.

PINHO, José Antônio G. de e SANTANA, Mercejane W "Inovação na gestão pública no Brasil: uma aproximação teórico-conceitual." In: ANAIS da ANPAD. Foz do 19uaçu: $22^{\circ}$ ENANPAD - Área Administração Pública, 1988.

SILVA, Paulo R. Guimarães e D’ARC, Hélène Rivière. Participação social: instrumento de gestão pública? Elementos para um debate sobre gestão de cidades brasileiras. Quais as perspectivas nos anos 90? Revista de Administração Pública. Rio de Janeiro: EBAP /FGV, número 2, 1996.

TENÓRIO, Fernando G., LUSTOSA, Frederico et alii. Pesquisa: Participação cidadã na gestão pública: práticas e representações sociais - Relatório marco legal da participação cidadã no Município do Rio de Janeiro. Cadernos EBAP. Rio de Janeiro: PEGS/EBAP/FGV, n 5, 1999.

e ROZENBERG, Jacob E. Gestão pública e cidadania: metodologias participativas em ação. Cadernos Gestão Pública e Cidadania. São Paulo: EAESP/ FGV, VoI. 7, 1997.

e CUNHA, P. G. Augusto. Relatório sobre as experiências semifinalistas do Programa Gestão Pública e Cidadania. Cadernos Gestão Pública e Cidadania. São Paulo: EAESP / FGV, Vol. 10, 1998.

Gestão social uma perspectiva conceitual In: Revista de Administração Pública. Rio de Janeiro: EBAP /FGV, 32(5): 7-23, set./ out. 1998.

e STORINO, Gylcilene Ribeiro. A sociedade é protagonista na relação com o Estado. Cadernos Gestão Pública e Cidadania. São Paulo: EAESP /FGV, no prelo, 1999. 